\title{
Comparison of color accuracy of commercial digital cameras and cellular phonecameras for laboratory purposes
}

Adeline W. Yuh

West Virginia University

Follow this and additional works at: https://researchrepository.wvu.edu/etd

\section{Recommended Citation}

Yuh, Adeline W., "Comparison of color accuracy of commercial digital cameras and cellular phonecameras for laboratory purposes" (2014). Graduate Theses, Dissertations, and Problem Reports. 179.

https://researchrepository.wvu.edu/etd/179

This Thesis is protected by copyright and/or related rights. It has been brought to you by the The Research Repository @ WVU with permission from the rights-holder(s). You are free to use this Thesis in any way that is permitted by the copyright and related rights legislation that applies to your use. For other uses you must obtain permission from the rights-holder(s) directly, unless additional rights are indicated by a Creative Commons license in the record and/ or on the work itself. This Thesis has been accepted for inclusion in WVU Graduate Theses, Dissertations, and Problem Reports collection by an authorized administrator of The Research Repository @ WVU. For more information, please contact researchrepository@mail.wvu.edu. 
COMPARISON OF COLOR ACCURACY OF COMMERCIAL DIGITAL CAMERAS AND CELLULAR PHONECAMERAS FOR LABORATORY PURPOSES

Adeline W. Yuh

\begin{abstract}
Thesis Submitted to the
School of Dentistry

At West Virginia University

for the degree of
Master of Science
In
Prosthodontics

in partial fulfillment of the requirements

\author{
Matthew Bryington, DMD, MS, Chair \\ Mark Richards, DDS, Med, FACP \\ Bryan Dye, DDS, MS \\ Department of Restorative Dentistry
}

Morgantown, West Virginia

2014

Key words:

Digital Cameras, cellular phone Cameras, Color Measurement, $\Delta \mathrm{E}$ 


\begin{abstract}
Comparison of color accuracy of commercial digital cameras and cellular phone cameras for laboratory purposes

Adeline W. Yuh
\end{abstract}

\begin{abstract}
Accurate shade matching of indirect restorations as well as accurate communication of that information to the laboratory technician is one of the most challenging tasks in the dental office. The objective of this study was to compare the color accuracy of commercial digital cameras used in the dental office with cellular phone cameras. Twenty four color patches and 4 shade tabs on a new Vita classic shade guide (A2, B2, $\mathrm{C} 2$, and D2) were photographed 3 times with 4 different cameras: The Canon EOS 30D, the Nikon D700, the iPhone 5 and the Galaxy S3. For the light source, a light box with D-65 desktop lamp was fixed on and optical table providing an optical set up of 0 observation and $45^{\circ}$ illumination to the object. $T$ he digital images were loaded to a personal computer and color values (RGB) for each image were calculated using the software program Adobe Photoshop. RGB values of the shade tabs were converted to CIE LAB value using Lindbloom color converter software. A total of $288 R G B$ values for the color patches and $48 \mathrm{CIE}$ LAB values for the shade tabs were obtained. The color difference value $(\triangle \mathrm{E})$ between the digital images and the manufacturer value was calculated. The $\triangle \mathrm{E}$ values were analyzed by one-way ANOVA and Tukey HDS test. For both the color patches and the shade tabs, the canon way EOS 30D demonstrated the lowest $\triangle \mathrm{E}$ value. Regarding the 24 color patches, The Tukey HDS test shows that the Nikon D700, the Canon EOS 30D and the Galaxy S3 cameras were not significantly different, meanwhile the iPhone 5 camera was significantly different to the other 3 cameras. However, for the digital image of shade tabs, The Tukey HSD test demonstrated that all cameras were significantly different to one another. Within the limitation of this study, the iPhone 5 was the least accurate in reproducing color of color patches as well as shade tabs, while the canon EOS 30D was the most accurate at reproducing shade tabs.
\end{abstract}




\section{DEDICATION}

This research project is dedicated first to my parents who instill the importance of education in all their children. It is also dedicated to my siblings; your unconditional love and support are what make me thick. Last, but not least, I am dedicating this work to my husband; I simply would not be in this place without you by my side. 


\section{ACKNOWLEDGEMENTS}

I would like to take this opportunity to thank many individuals who have made this project possible

Dr. Matthew Bryington, my committee chair, for his help and guidance throughout the project. You made this project possible from the birth of the idea to the execution of the project itself. I will always be grateful for that.

Drs. Mark Richards and Bryan Dye, my committee members, I thank them for their guidance through the project and their wonderful instruction throughout the prosthodontics residency.

Dr. Gerry Hobbs and John Honaker, for your help in helping me interpret the results of the research project.

A very special thank you goes to Dr. Rafat Amer at The Ohio State University. I am very grateful for the set up and materials you made available to me. The time and guidance you provided me were very valuable. 


\section{TABLE OF CONTENTS}

COMPARISON OF COLOR ACCURACY OF COMMERCIAL DIGITAL CAMERAS AND CELLULAR PHONECAMERAS FOR LABORATORY PURPOSES

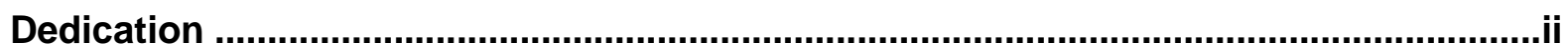

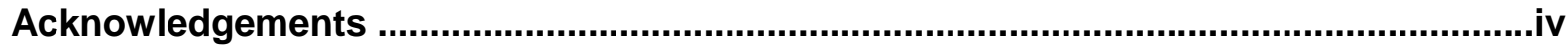

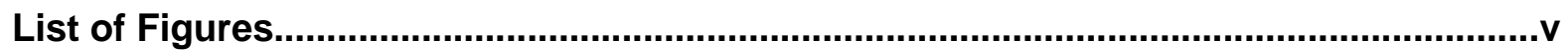

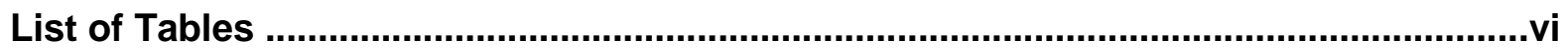

CHAPTER I Introduction

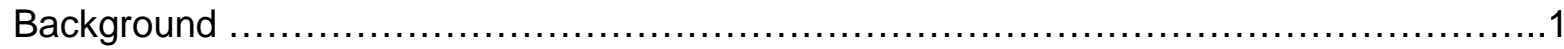

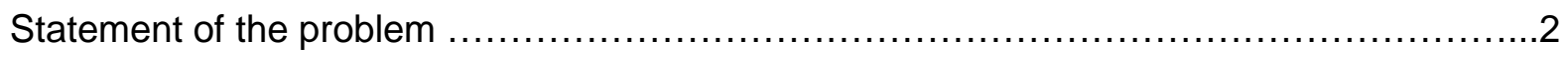

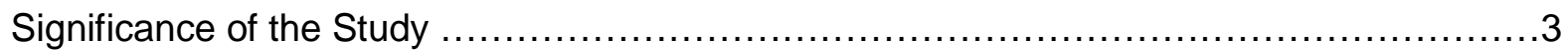

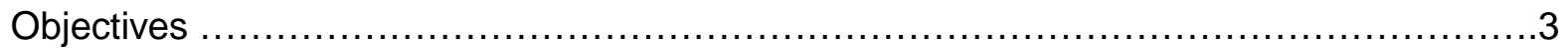

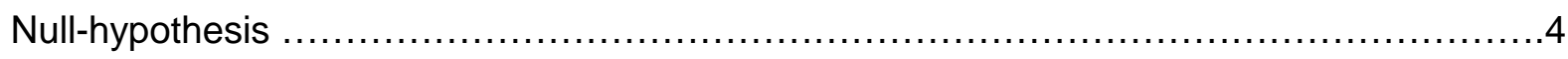

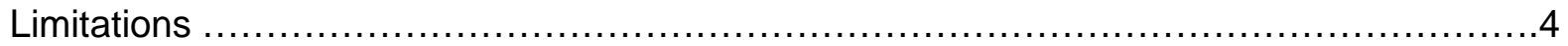

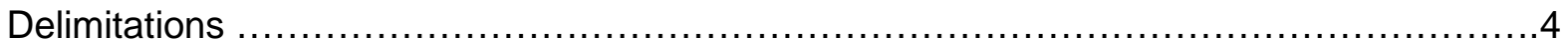

Chapter II Review of Literature and color science

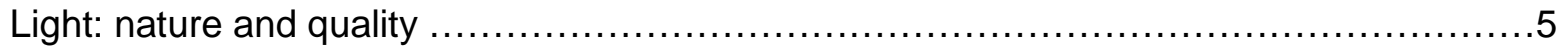

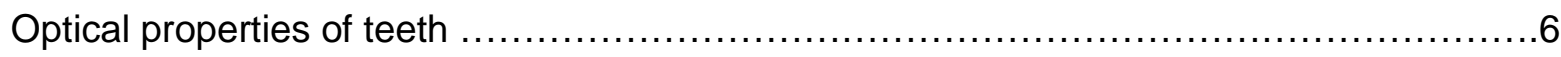

Description of color and color measurement …...........................................

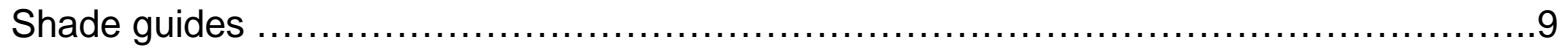

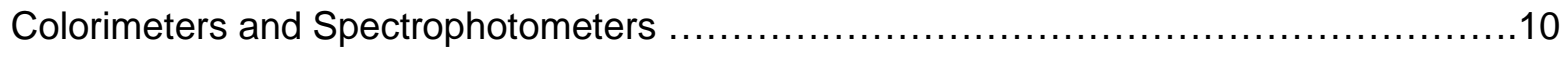

Chapter III

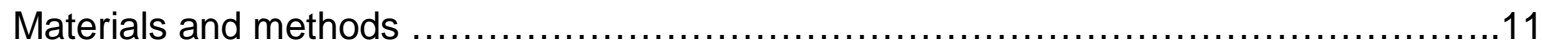

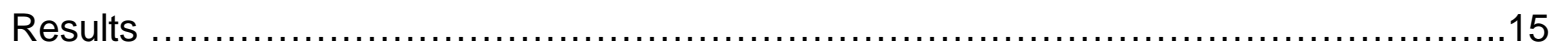

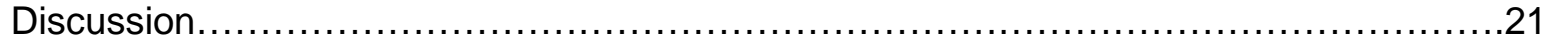

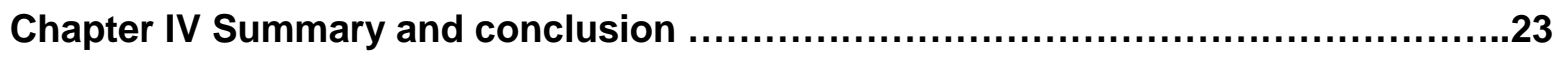

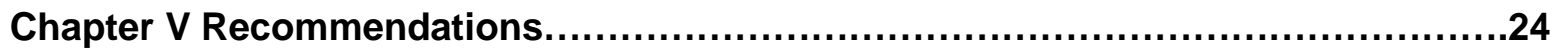

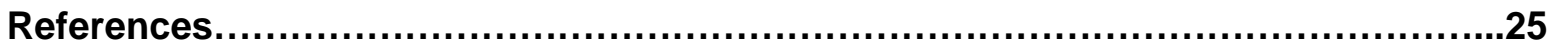




\section{LIST OF TABLES}

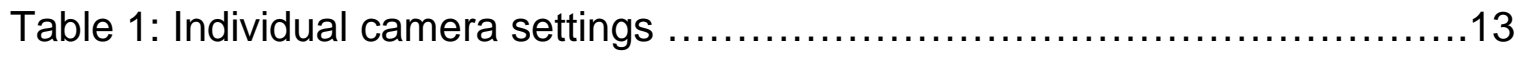

Table 2: Raw $\Delta \mathrm{E}$ values for Colorchecker card ................................16

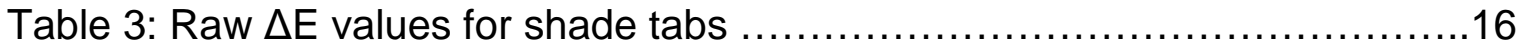

Table 4: Analysis of variance for colorchecker card ............................18

Table 5: Tukey HSD for colorchecker card …................................18

Table 6: Pairwise comparison of cameras for colorchecker card images ..........19

Table 7: Analysis of variance for shade tabs ....................................20

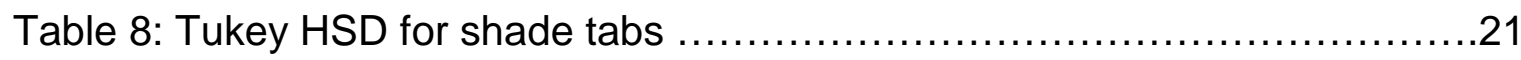

Table 9: Pairwise comparison of cameras for shade tabs ........................21 


\section{LIST OF FIGURES}

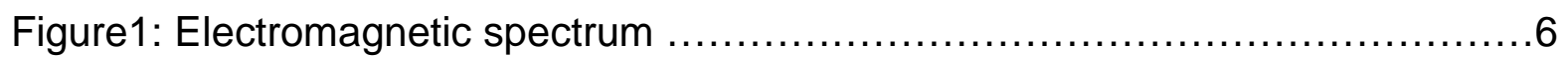

Figure 2: Schematic view of the experiment set up .................................12

Figure 3: Digital image of the colorchecker card ....................................13

Figure 4: Shade tab image taken with Nikon D700 ...............................14

Figure 5: Box plot (distribution of $\Delta \mathrm{E}$ per camera types) for color checker cards......17

Figure 6: Box plot (distribution of $\Delta \mathrm{E}$ per camera types) for shade tabs ...............17 


\section{CHAPTER I: INTRODUCTION}

\section{BACKGROUND}

Accurate shade matching of direct and indirect restorations is one of the most challenging tasks in the dental office. The esthetic knowledge and demands of patients keep increasing. Many authors have conducted studies where subjects have to perform shade matching; Barret et al. (2002) found $70 \%$ of successful shade matching with subjects with normal color vision ${ }^{1}$; Klemetti et al.(2006) reported that successful shade matching varied between $53 \%$ and $71 \%^{2}$; Hammad (2003)found success rate of dental professional varies between $35 \%$ and $67 \% .{ }^{3}$ Color science and shade selection are complex topics, paradoxically, Paravina et al. reported after a 2009 survey sent to dental school around the world that the number of hours dedicated to color-related topics was $4.0 \pm 2.4$ for predoctoral levels and $5.5 \pm 2.9$ for postdoctoral levels. ${ }^{4}$

It is critical for practitioners to provide restorations that are harmonious with the rest of the patient dentition. To duplicate the color of a natural tooth for an indirect restoration, three procedures are required: determination of the tooth shade clinically, communication of the shade to a dental laboratory technician, and shade reproduction in dental porcelain. ${ }^{5}$

Visual color determination, by comparison of the tooth with a standard commercial shade guide is still the most frequently applied method in dentistry as it is a quick procedure. But, historically, assessing shade visually has been characterized by several difficulties: the shade guides vary between batches, metamerism occurs as the 
standardized illuminating light varies. The observer mood, fatigue, overall experience and physical limitations (color blindness) are known to influence visual shade selection. This technique is subjective, inconsistent and not reliable. ${ }^{6}$ Despite these difficulties, the human eye can discern very small differences in color, however the ability to communicate the degree and nature of these differences is lacking.

Today, digital cameras with a ring flash are used in the dental office for treatment planning, case documentation, communication with the patient, shade selection and communication with the laboratory technician and marketing purposes. Most commercial digital cameras acquire red, green and blue image information that is utilized to create a color image. The RGB color model is an additive model in which red, green and blue light are added together in various ways to produce a broad array of colors. ${ }^{7}$ Digital cameras, alone or combined with electronic devices like colorimeters and spectrophotometers may improve the reliability of shade matching. ${ }^{7,8}$ The advantage in using digital cameras is that they communicate not just shade but texture and translucency to the laboratory. The Type of camera used in dentistry is digital single lens reflex (DSLR) camera.

\section{STATEMENT OF THE PROBLEM}

Most dentists are not professional photographer and for novice photographers, a DSLR camera and the recommended accessories (lenses, flashes, etc.) can be too complicated and intimidating. These cameras are cumbersome with many settings options. Even though they are becoming more affordable, they are not inexpensive. In contrast, the cellular phone cameras are smaller, cheaper and readily available. They 
are also easy to use. For most of them, the instruction of use consists of aiming and shooting. They also offer faster internet connection than commercial digital camera used in dentistry.

\section{SIGNIFICANCE OF THE STUDY}

According to pew research, most adults in America own cellular phones. Most cell phones have built in Camera. In today's world cell phone cameras are used to record and document every facets of life. Dental students are constantly using their cellular phone in the clinic floor to document patient condition. Even patients used their own cellular phone to take selfies during treatment.

\section{OBJECTIVES}

The interest in color research has increased significantly over the past several decades. When Keywords color and dentistry were used for Medline research, only 107 papers were found by 1970 . In subsequent decades the number of references increased as follows: 409(1980), 1134(1990), 2259 (2000), 4062(April 2010). ${ }^{7}$ Some of these recent studies have evaluated the use of commercial digital cameras in dentistry, yet there is still no documentation on the use of cellular phone cameras in dentistry.

The objective of this study was to compare the color accuracy of commercial digital cameras commonly used in dentistry today with cell phone cameras for shade matching and communication. 


\section{NULL-HYPOTHESIS}

No statistically significant difference will be found between the color difference $(\Delta E)$ of the 4 cameras, whether for the colorchecker card or for the shade tabs.

\section{LIMITATIONS}

The study did not include the use of natural teeth, in vitro or in vivo, so the results should not necessarily be extrapolated to clinical situations results. For the shade tabs, the color measurement of digital images were compare to known value of similar shade tabs, but Schwabacher and Goodkind (1990), Cal et al. (2004) ${ }^{9,10}$ reported on inconsistency between different batches of shade guides from the same manufacturer. The shade guide used, Vita classic shade does not represent the full extent of the natural teeth shades.

\section{DELIMITATIONS}

The sample size for the shade guide was very small, not only one type of shade guide was represented, but also the sample consisted of only 4 out of the 16 shade tabs that existed on the shade guide. 


\section{CHAPTER II:REVIEW OF LITERATURE AND COLOR SCIENCE}

\section{LIGHT: Nature and Quality}

Color is complex and encompasses both subjective and objective phenomena. It is important to understand the nature of light and how the eye perceives and the brain interprets light as color in order to successfully match shade in dentistry, The quality and quantity of light source in which tooth shade is being matched has definite effects on the type of color being perceived. Light physics considers three variables in determining color: 1) light source(s), which illuminate(s) the object; 2) object - reflects, absorbs, transmits the incident light, and 3) observer (human eye,

instrument): perceives, processes and interprets the reflected light. ${ }^{11}$

Scientifically, light is described as visible electromagnetic energy whose wavelength is measured in nanometers $(\mathrm{nm})$. The human eye is sensitive only to the visible (white light) part of the of the electromagnetic spectrum, it is a narrow band comprise between $380 \mathrm{~nm}$ and $750 \mathrm{~nm}$ ( fig 1). When white light is made to pass through a crystal prism, as was done by Sir Isaac Newton in 1676, it is bent, and each wavelength changes direction by a different amount and the individual colors of the visible spectrum are seen.

A light source of appropriate quality for shade selection should contain a full spectrum of rays without the dominance of any wavelength. 


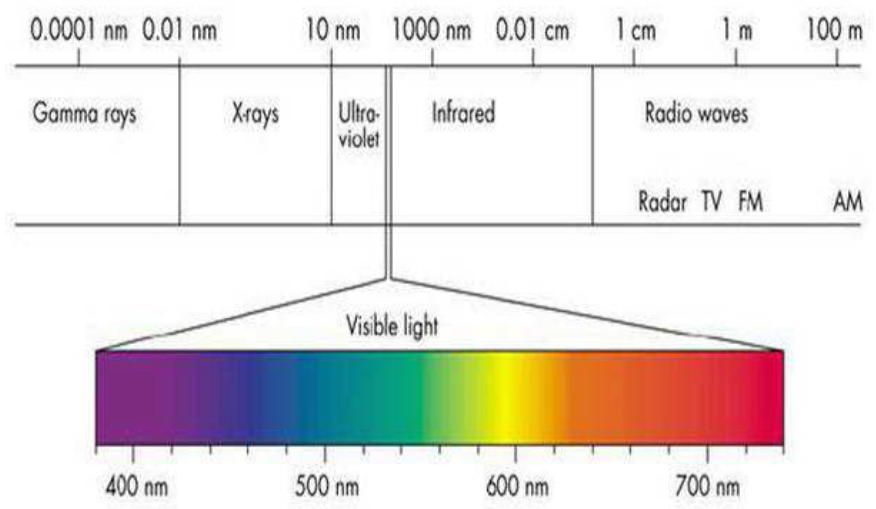

Figure 1. Electromagnetic spectrum

Color temperature and color rendering index are used to measure the capacity to reproduce standard daylight. ${ }^{12}$ The color rendering index (CRI), on a scale of 1 to 100 , indicate how well a particular light source renders color as compared to a specific standard source. Northern daylight is considered the best because it is closest to emitting the full spectrum of white light. It is used as the standard by which to judge other light sources. It has $\mathrm{CRI}$ close to 100 . Unfortunately, the most common light sources in dental operatories are incandescent and fluorescent. Neither is ideal for shade matching, thus Color-corrected fluorescent lighting with CRI between 90 and 100 is recommended in dental operatories. ${ }^{12}$

\section{OPTICAL PROPERTIES OF TEETH}

The color of a tooth is determined by a combination of its optical properties including translucency, fluorescence and opalescence (1). When light encounters a tooth, four phenomena associated with the interactions of the tooth with the light flux can be described: (1) specular transmission of the light through the tooth,(2) specular reflection 
at the surface,(3)diffuse light reflection at the surface and (4) absorption and scattering of light within the dental tissues. ${ }^{13}$ VaarKamp et al. determined that enamel hydroxyapatite crystals contribute to light scattering while dentin provides the optical anisotropy observed, supporting the idea that tubules are the predominant cause of scattering. ${ }^{14}$ Tooth color is mainly determined by the color of dentin. Bosch and Coops (1995) showed in an in vitro study that the colors of 28 teeth from different patients where enamel were removed correlated strongly with the colors of the complete tooth. ${ }^{15}$ The influence of fluorescence in the overall tooth color is controversial. Terry DA et al. reported that the combination of fluorescence from dentine and enamel enhance the whiteness or value of teeth ${ }^{16}$. In contrast, Ten Bosch and Coops ${ }^{13}$ measured the color of tooth samples under two different light sources and concluded that under everyday lighting conditions, fluorescence does not contribute measurably to visually observed tooth color. Seghi RR and Johnston (1992) also concluded that fluorescence does not play a significant role in dental shade matching. ${ }^{17}$

\section{DESCRIPTION OF COLOR AND COLOR MEASUREMENT}

There are two systems used to describe color in dentistry: the descriptive Munsell color system and the more quantitative CIELAB (Commission International de l'Eclairage) system.

The Munsell system describes color in three attributes: hue, Chroma and value. Hue is defined as the actual color such as red, yellow, blue, and so on. Chroma is the saturation or intensity of the hue while value is the degree of lightness or darkness.

Sproull in a series of article in $1973^{18,19}$ described the three dimensional nature of 
color, its relationship with the dental shade guide and practical application of the organization of color. According to Sproul, The Munsell color solid can be likened to a sphere or to a cylinder as it is an irregular three dimensional figure that has characteristics of both. The relationship of one color to another becomes apparent when the organization of the color within the three dimensional solid is understood. A colorless or achromatic axis extends through the center of the cylinder, pure white at the top and pure black at the bottom. Colors(Hues) are arranged around this axis and within each Hue, the colors are arranged in scales according to their lightness/Darkness(value) and their purity or strength(Chroma).

The Commission Internationale de l'E'clairage $(\mathrm{CIE})(1931)$ is an organization devoted to standardization in areas such as color and appearance. They defined a color space system called CIELab in 1976. The CIE Lab color space represents a uniform color space, with equal distances corresponding to equal perceived color differences. It describes color as the product of blending three color coordinates; $L^{*}, a^{*}$ and $b^{*}$. The $L^{*}$ is the lightness ranging from white to black, $a^{*}$ is the redness ranging from green to red, and $b^{*}$ is the yellowness ranging from yellow to blue. ${ }^{20}$ It is mostly used for color research in dentistry. One advantage of the CIElab system is that it can also numerically quantify the color difference $(\Delta \mathrm{E})$ between two objects using the following formula $\Delta \mathrm{E}=$ the square root of $[(\mathrm{L} 1-\mathrm{L} 2) 2+(\mathrm{a} 1-\mathrm{a} 2) 2+(\mathrm{b} 1-\mathrm{b} 2) 2]$. According to Kuehni and Marcus(1979), under controlled lighting conditions the smallest color difference detectable by the human eye is $1 \Delta \mathrm{E} .{ }^{21}$ This means that a $1 \Delta \mathrm{E}$ is the $50: 50$ perceptibility threshold under controlled lighting conditions; that is $50 \%$ of observers will notice a difference and $50 \%$ will not. Johnston and Kao (1989), then 
Ragain and Johnston(2000) found that acceptable color difference can range from 2.72 to 3.3 for in vitro studies to 6.8 in an in-vivo study. ${ }^{22,23}$

\section{SHADE GUIDES}

Clark introduced a custom shade guide in 1931 based on visual assessment of human teeth, recorded in Munsell's Hue, Value and Chroma. Sproull, in the early 70s, suggested that an ideal shade guide should consist of shade (color) tabs that are well distributed and logically arranged in color space, preferably based on the Munsell color system

The Vitapan Classical Shade Guide, formerly Vita Lumin (Vita Zahnfabrik, H. Rauter GmbH \& Co.KG, Bad Säckingen, Germany)was introduced in 1956 and has been the gold standard ever since. It is still the most used shade guide for porcelain crown even though its shortcomings are well documented. The Vitapan classical shade guide does not completely cover the entire color spectrum of natural teeth. King and DeRijk in 2007 observed after comparing the shade tabs of 26 new Vitapan shade guides that the differences between shade guides were large, with a variation in $\Delta \mathrm{E}$ of 3.05 between shade tabs of the same shade $(\mathrm{C} 1)$ was larger than the differences between different shades and therefore, the Vitapan Classical Shade Guide tabs should not be considered interchangeable. ${ }^{24}$ Goodkind and schwabacher (1990) ${ }^{9}$ observed that the tabs are not a uniform color, the shade guides vary between batches. Another shade guide is the Chromascop (Ivovlar-Vivadent, Schaan, Liechtenstein). It uses numbers to distinguish hue, e.g., 100 (white), 200 (yellow), 300 (orange), 400 
(grey) and 500 (brown). Chroma is indicated by another set of numbers, 10 are high value with low Chroma, while 40 is low value with high Chroma.

In the late 1990s, Vita introduced the 3D-Master shade guide. It features a systematic colorimetric distribution of 26 shade tabs within the tooth color space. The manufacturer claims that this shade guide demonstrates an equidistant distribution in the color space (delta $E$ of 4 CIELAB units in the lightness and 2 CIELAB units in Hue and Chroma. The shade guide is organized into five primary value levels, with a secondary distribution based on Chroma and hue

\section{COLORIMETERS AND SPECTROPHOTOMETERS}

In order to improve visual shade matching, electronic instruments have been developed. A colorimeter analyzes the reflected light from an object after it has been passed through red, blue and green filters. Colorimeters provide measurement in CIELab units $\left(L^{*} a^{*}\right.$ and $\left.b^{*}\right)$ allowing objective comparison of two objects, but research results have been controversial. Seghi et al. (1989) concluded that color measurement by a colorimeter gives a consistent color evaluation ${ }^{25}$; Douglas(1997) in an in vivo study determined that a colorimeter equipped with a custom positioning jig had acceptable precision for intraoral measurement of longitudinal changes in tooth color. ${ }^{26}$ In contrast though, Haywood and Leonard (1994) has postulated that colorimeters are designed for flat surfaces rather than the curved translucent surfaces found on teeth which is supported by Okubo et al.(1998) findings that accuracy of a new colorimeters(colortron II) was only slightly better than shade determination by visual means for porcelain shade guide teeth. ${ }^{27,6}$ 
Spectrophotometers are another type of electronic device used for shade matching. A spectrophotometer emits a white light into a spectrum of wavelength bands between 5 $\mathrm{nm}$ and $20 \mathrm{~nm}$ to illuminate the measured object. It then measures the wavelength reflected from the illuminated object. The software calculates the values for $L^{*} a^{*}$ and $b^{*}$ and then determines the closest shade by determining the smallest $\Delta \mathrm{E}$ value between a particular shade and the measured object. ${ }^{20}$ Paul et al. (2002) compared 2 portable devices and determined that Compared with observation by the human eyes or conventional techniques, they found that spectrophotometers offered a $33 \%$ increase in accuracy and a more objective match in $93.3 \%$ of cases. ${ }^{28}$

\section{CHAPTER III}

\section{MATERIALS AND METHODS}

\section{A-Color Measurement}

A D-65 desktop lamp(Sol-Source, GretagMacbeth, New Windsor, NY,USA) was fixed on an optical table (Mecom Inc., Risingsun, $1 \mathrm{H}, \mathrm{USA}$ ), providing an optical setup of $0^{\circ}$ Observation and $45^{\circ}$ illumination to the object. Fig 2. For all color measurements in this study, spectral reflectance were obtained from 380 to $780 \mathrm{~nm}$ with a $2 \mathrm{~nm}$ interval and subsequently converted to RGB values (D65 illumination and $2^{\circ}$ observer). Distance from Observer to object was change to allow for best image captures. Distance from Observer to object for each camera can be found in table 1. 


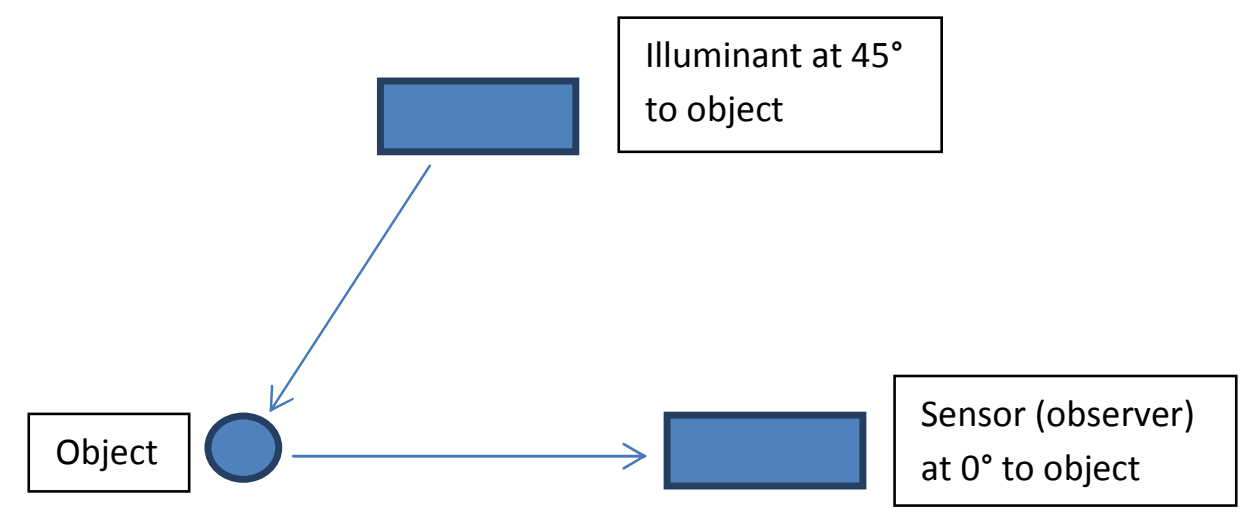

Figure 2. Schematic view of the experimental set up

To evaluate accuracy, color measurement were carried out on 24 color patches and 4 shade tabs on a new Vita shade guide: A2, B2, C2, and D2. Each shade tab and color patch was shot 3 times. These color measurements were compared with the known manufacturer RGB values.

\section{B-Images Samples}

Four cameras were used to capture the image of 24 color on a colorchecker classic card (fig3)and 4 shade tabs,A2, B2, D2, D2 from a new VITA classic shade Guide(fig 4): (1) the Canon EOS 30D(Canon USA, Inc., Melville, NY),(2) Nikon D700(Nikon Corporation, Tokyo, Japan), (3) iPhone 5 camera(Apple Inc.,Cupertino,CA), (4) Galaxy S3 camera( Samsung Electronics Co.,Ltd, Suwon, South Korea). A tripod was use for 
the stability of the cameras and the distance from the cameras to the object was calculated. The setting of each camera and the distance from observer to object can be found in table 1.

Table 1: Individual camera settings for digital image samples.

\begin{tabular}{|l|l|l|l|l|}
\hline & Canon & NikonD700 & iPhone 5 & Galaxy S3 \\
\hline Operation mode & Manual & Manual & N/A & N/A \\
\hline ISO & 200 & 200 & N/A & 200 \\
\hline F-Stop & $4 / 2.8$ & 4 & 2.2 & 2.6 \\
\hline Shutter Speed & $1 / 125$ & $1 / 125$ & N/A & N/A \\
\hline White balance & Sun daylight & Sun daylight & N/A & Daylight \\
\hline $\begin{array}{l}\text { Distance from } \\
\text { camera to object }\end{array}$ & $\begin{array}{l}100 \mathrm{~cm} \text { (color } \\
\text { card)/ }\end{array}$ & $\begin{array}{l}89 \mathrm{~cm} \text { (color card / } \\
56 \mathrm{~cm} \text { (Shade tabs) }\end{array}$ & $\begin{array}{l}60 \mathrm{~cm} \text { (Shade tabs) } \\
16.5 \mathrm{~cm} \text { (Shade } \\
\text { tabs) }\end{array}$ & $\begin{array}{l}64 \mathrm{~cm} \text { (color card / } \\
16.5 \mathrm{~cm} \text { (Shade } \\
\text { tabs) }\end{array}$ \\
\hline Image format & Raw & Raw & N/A & N/A \\
\hline
\end{tabular}

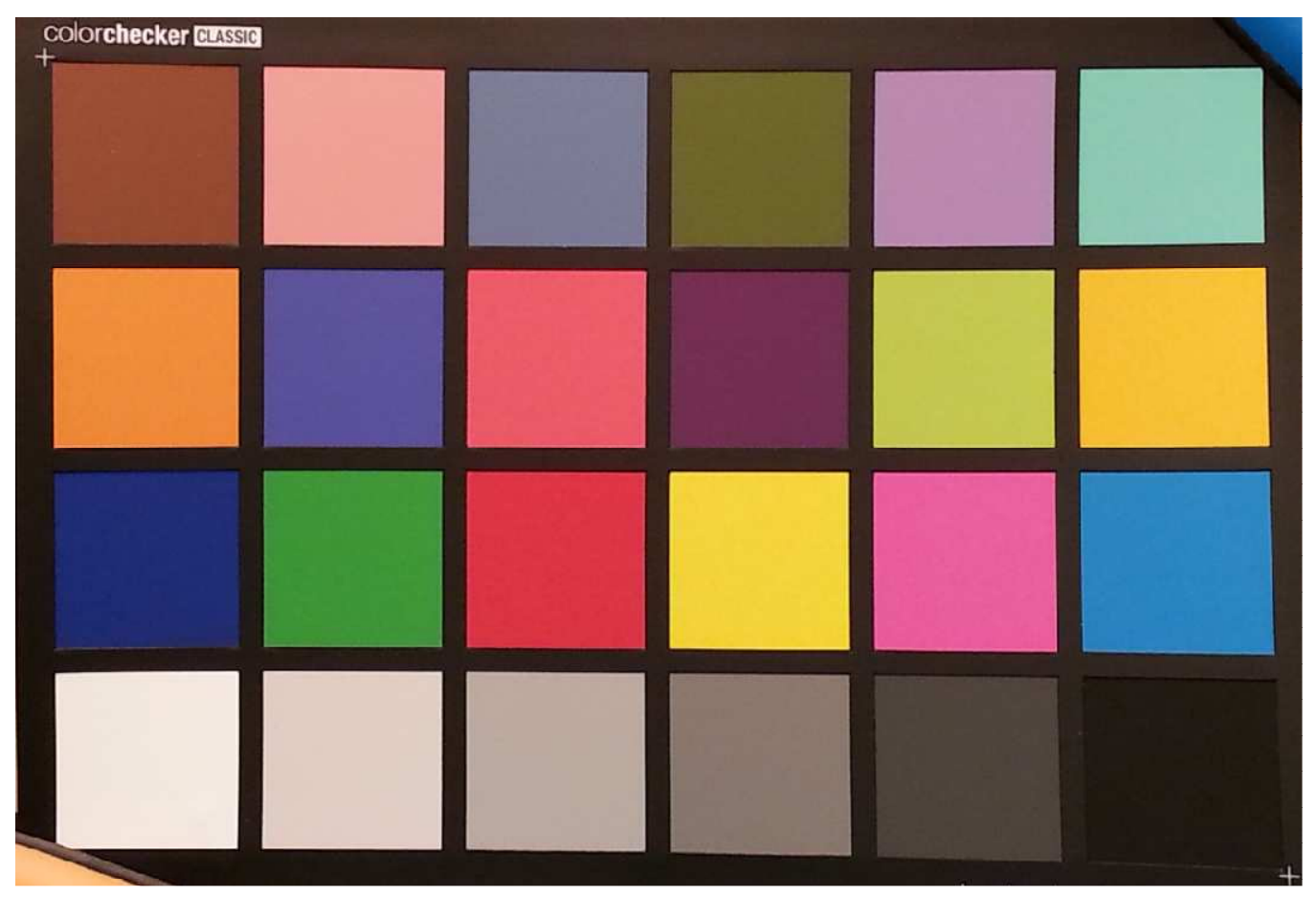

Figure 3: Digital image of colorcheker card: 24 color patches. 


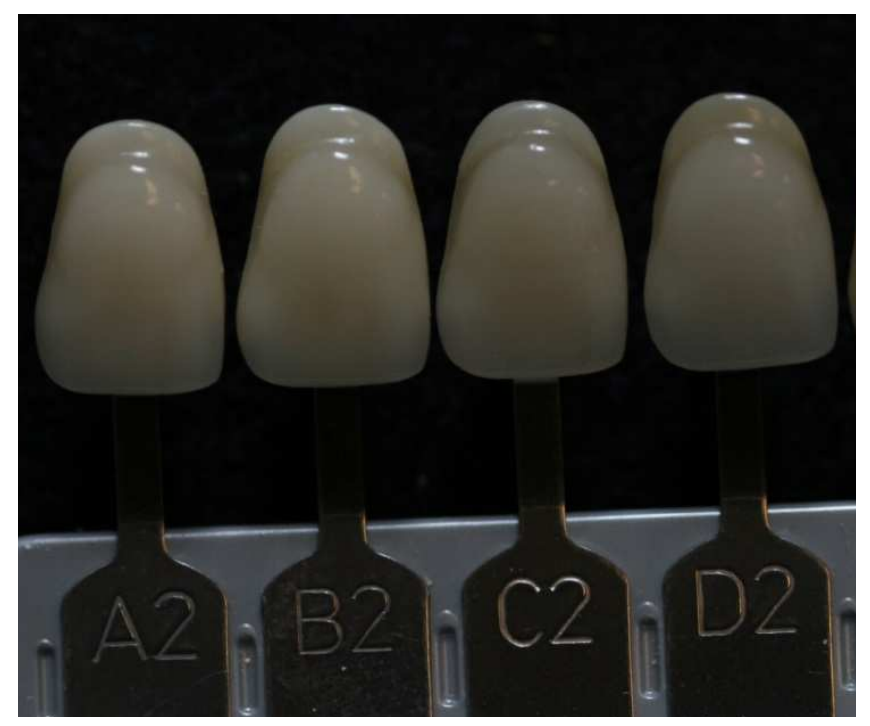

Figure 4: Shade tab image taken with Nikon D700

\section{C-Image Analysis}

Colorchecker classic images: The digital images of the color patches were transferred to a personal computer and evaluated with Adobe Photoshop version CS5.1. Each of the 24 color patches was captured 3 times with each camera. The "pointer tool" was placed in the center of each patch, color values (RGB) were calculated using Adobe Photoshop image date pane. The RGB values obtained from the digital images were compared with the RGB values of color checker classic card provided by the manufacturer X-Rite, Inc. (Grand Rapids, MI) and the color difference value $\Delta \mathrm{E}$ was calculated using Babelcolor CT\&A software. For each camera, three $\Delta \mathrm{E}$ values were calculated for each color patch and the average $\Delta E$ was obtained.

Shade Tabs images: The digital images of the shade tabs A2, B2, C2, and D2 were loaded into Photoshop. A measurement template was created in the middle of the tab. RBG color values were recorded following the method as described above. Mean 
values were converted to CIELAB values using Lindbloom color converter software (www.brucelindbloom.com; Jacksonville, Florida). The $\Delta \mathrm{E}$ was measured by comparing the CIE LAB value from the digital images with the CIE LAB value reported by Kuo.s (2003) using Babelcolor CT\&A as describe above. ${ }^{29}$ For each camera, $3 \Delta \mathrm{E}$ measurements were made for each shade tab and the average was calculated.

\section{D-Statistical Analysis}

A one-way analysis of variance was used to compare differences of $\Delta \mathrm{E}$ values among the 4 cameras. The Tukey HSD test $(\alpha=0.050)$ was used to determine significant difference between means.

\section{RESULTS}

For both the colorchecker card and the shade tabs, The Canon EOS $30 \mathrm{D}$ camera has the lowest mean $\Delta \mathrm{E}$ and the iPhone 5 has the highest mean $\Delta \mathrm{E}$ (table 2 and Table 3). 


\begin{tabular}{|l|r|r|r|r|}
\hline & Canon & Nikon & iPhone5 & \\
\hline 1. Dark skin & 9.31 & 10.4 & 20.6 & 19 \\
\hline Light Sk & 9.65 & 12.3 & 23.1 & 17 \\
\hline Blue sk & 9.79 & 8.15 & 19.2 & 3.38 \\
\hline Foliage & 10.1 & 15.7 & 19.1 & 9.4 \\
\hline 5.Blue FI & 2.74 & 4.93 & 20.5 & 14.1 \\
\hline Bluish gr & 5.61 & 7.01 & 30.3 & 11.2 \\
\hline Orange & 21.8 & 22.6 & 23.9 & 8.13 \\
\hline Purplish B & 9.3 & 17.7 & 29.5 & 5.16 \\
\hline Mod Red & 12.8 & 13 & 31 & 17.9 \\
\hline 10. Purple & 7.56 & 12.6 & 25.8 & 11.1 \\
\hline Yellow G & 7.42 & 14.8 & 24.5 & 7.23 \\
\hline Orange Ye & 14.1 & 16.7 & 26.2 & 15.9 \\
\hline blue & 7.26 & 19.5 & 37.6 & 12.6 \\
\hline green & 13.4 & 12 & 39.2 & 35.5 \\
\hline 15.red & 17.5 & 15 & 40.6 & 23.3 \\
\hline yellow & 12.8 & 9.72 & 25.6 & 9.84 \\
\hline Magenta & 9.24 & 15.4 & 36.3 & 18 \\
\hline Cyan & 5.44 & 18.9 & 17.7 & 24.4 \\
\hline White & 11.3 & 12.3 & 3.35 & 8.15 \\
\hline 20.Neut 8 & 6.12 & 5.76 & 12.4 & 1.86 \\
\hline neutral 6.5 & 5.04 & 3.1 & 11.3 & 2.76 \\
\hline neutral 5 & 8.29 & 15.9 & 8.16 & 2.72 \\
\hline neutral3.5 & 7.87 & 8.59 & 2.65 & 12.3 \\
\hline black & 10.6 & 7.17 & 11.6 & 15.8 \\
\hline MEAN & 4.971916 & 11.3191 & 18.94112 & 10.18343 \\
\hline STANDARDN DEVIATION & & & & \\
\hline & & & \\
\hline
\end{tabular}

Table 2. Raw Delta E values for colorchecker card.

\begin{tabular}{|l|r|r|r|r|}
\hline & Canon & Nikon & iPhone 5 & S3 \\
\hline A2 & 6.67 & 10.4 & 30.1 & 22.3 \\
\hline B2 & 7.59 & 11.9 & 30.5 & 21.1 \\
\hline C2 & 7.77 & 16.1 & 34.6 & 25.7 \\
\hline D2 & 6.85 & 11.1 & 29.6 & 21 \\
\hline Mean & 7.204765 & 12.19501 & 31.13928 & 22.44838 \\
\hline Standard D & 0.468722 & 2.215147 & 1.988718 & 1.903122 \\
\hline
\end{tabular}

Table 3. Raw Delta E values for Shade tabs. 
Figure 5 and 6 represent the distribution of $\Delta E$ per camera types ( Box plot) for the colorchecker card and the shade tabs respectively.

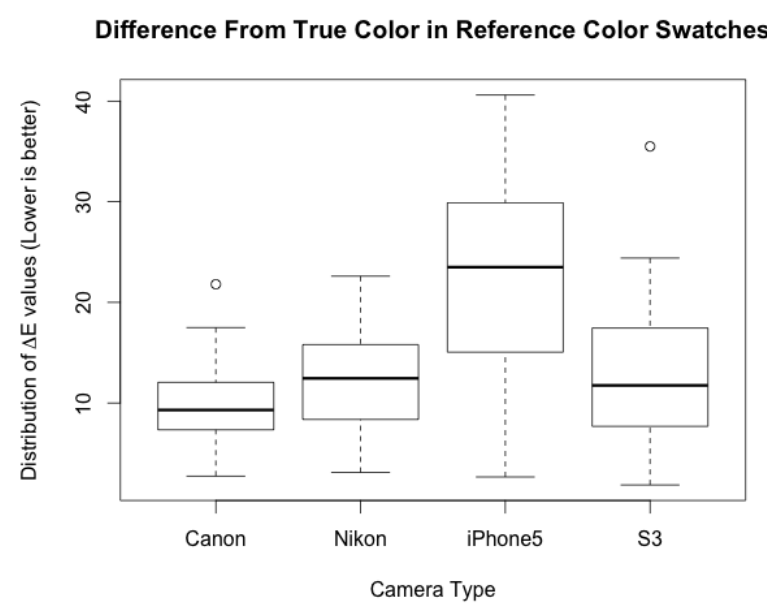

Figure 5. Box plot for color checker cards.

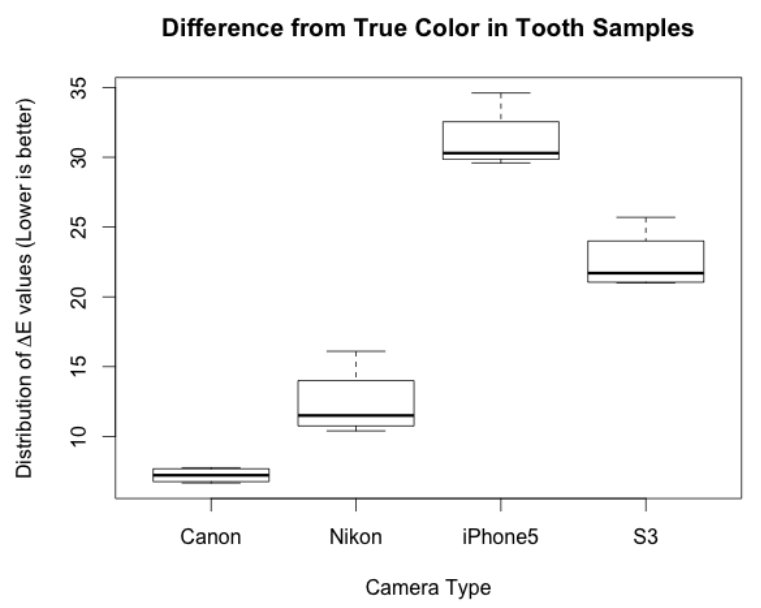

Figure 6. Box plot for shade tabs.

The comparison of $\triangle \mathrm{E}$ means for the 24 color patches using a one-way ANOVA is presented on table 4.

$\begin{array}{lrrrr}\text { Source } & \text { DF } & \begin{array}{r}\text { Sum of } \\ \text { Squares }\end{array} & \text { Mean Square } & \text { F Ratio } \\ \text { Model } & 26 & 4689.2987 & 180.358 & 4.7872 \\ \text { Error } & 69 & 2599.5501 & 37.675 & \text { Prob }>\text { F } \\ \text { C. Total } & 95 & 7288.8488 & & <.0001^{*}\end{array}$

\section{Effect Tests}

$\begin{array}{lrrrrr}\text { Source } & \text { Nparm } & \text { DF } & \begin{array}{r}\text { Sum of } \\ \text { Squares }\end{array} & \text { F Ratio } & \text { Prob }>\text { F } \\ \text { Color } & 23 & 23 & 2450.2247 & 2.8277 & 0.0005^{*} \\ \text { Label } & 3 & 3 & 2239.0740 & 19.8106 & <.0001^{*}\end{array}$


Source Nparm DF $\quad$ Sum of F Ratio Prob $>$ F Squares

Table 4. Analysis of Variance for colorchecker cards.

The Tuckey HSD test and the matched pair test for the 24 color patches showed that The Canon EOS 30D,the Nikon D700 and the Galaxy S cameras were not statistically significantly different $(P<0.0001)$. The iPhone 5 was statistically different to all the other 3 cameras (Table 5 and table 6).

\section{LSMeans Differences Tukey HSD}

$\alpha=0.050 \quad Q=2.63276$

LSMean[i] By LSMean[j]

\begin{tabular}{|l|r|r|r|r|}
\hline Mean[i]-Mean[i] & Canon & iPhone5 & Nikon & S3 \\
Std Err Dif & & & & \\
Lower CL Dif & & & & \\
\hline Canor CL Dif & & & & \\
& 0 & -12.713 & -2.6746 & -2.9871 \\
& 0 & 1.77188 & 1.77188 & 1.77188 \\
& 0 & -17.378 & -7.3395 & -7.652 \\
& 0 & -8.0484 & 1.99035 & 1.67785 \\
\hline iPhone5 & 12.7133 & 0 & 10.0388 & 9.72625 \\
& 1.77188 & 0 & 1.77188 & 1.77188 \\
& 8.0484 & 0 & 5.37381 & 5.06131 \\
& 17.3783 & 0 & 14.7037 & 14.3912 \\
\hline Nikon & 2.67458 & -10.039 & 0 & -0.3125 \\
& 1.77188 & 1.77188 & 0 & 1.77188 \\
& -1.9904 & -14.704 & 0 & -4.9774 \\
& 7.33952 & -5.3738 & 0 & 4.35244 \\
\hline
\end{tabular}




\begin{tabular}{|l|r|r|r|r|}
\hline S3 & 2.98708 & -9.7263 & 0.3125 & 0 \\
& 1.77188 & 1.77188 & 1.77188 & 0 \\
& -1.6779 & -14.391 & -4.3524 & 0 \\
& 7.65202 & -5.0613 & 4.97744 & 0 \\
\hline
\end{tabular}

Table 5. Tukey HSD table colorchecker card.

Level

iPhone5 A

S3

B

Nikon

B

Canon

B

Levels not connected by same letter are significantly different
Least Sq Mean

22.506667

12.780417

12.467917

9.793333

\begin{tabular}{|l|l|l|}
\hline Pair wise & comparison & P-value \\
\hline Nikon & Canon & 0.0097 \\
\hline iPhone 5 & Canon & $<0.0001$ \\
\hline iPhone 5 & Nikon & $<0.0001$ \\
\hline Galaxy S3 & Canon & 0.0819 \\
\hline Galaxy S3 & Nikon & 0.8606 \\
\hline Galaxy S3 & iPhone 5 & $<0.0001$ \\
\hline
\end{tabular}

Table 6. Pairwise comparison of cameras for colorchecker card images

The comparison of $\Delta \mathrm{E}$ means for the 4 shade tabs using a one-way ANOVA is presented on table 7 .

Effect Tests

Source Nparm DF $\begin{gathered}\text { Sum of } \\ \text { Squares }\end{gathered}$ F Ratio Prob $>$ F 


$\begin{array}{lrrrrr}\text { Source } & \text { Nparm } & \text { DF } & \begin{array}{r}\text { Sum of } \\ \text { Squares }\end{array} & \text { F Ratio } & \text { Prob > F } \\ \text { Shade Tab } & 3 & 3 & 40.0677 & 11.1857 & 0.0022^{*} \\ \text { Label } & 3 & 3 & 1368.5162 & 382.0501 & <.0001^{*}\end{array}$

Table 7. ANOVA table for shade tabs.

The Tuckey HSD test and the matched pair test for the shade tabs showed that all the 4 cameras were statistically different to one another( P-value $<0.0001)$ Table8 and 9

\section{LSMeans Differences Tukey HSD}

$\alpha=0.050 \quad Q=3.1218$

LSMean[i] By LSMean[j]

\begin{tabular}{|c|c|c|c|c|}
\hline $\begin{array}{l}\text { Mean[i]-Mean[j] } \\
\text { Std Err Dif } \\
\text { Lower CL Dif } \\
\text { Upper CL Dif }\end{array}$ & Canon & I phone 5 & Nikon & S3 \\
\hline Canon & $\begin{array}{l}0 \\
0 \\
0\end{array}$ & $\begin{array}{r}-23.98 \\
0.77266 \\
-26.392 \\
-21.568\end{array}$ & $\begin{array}{c}-5.155 \\
0.77266 \\
-7.5671 \\
-2.7429\end{array}$ & $\begin{array}{l}-15.305 \\
0.77266 \\
-17.717 \\
-12.893\end{array}$ \\
\hline iPhone 5 & $\begin{array}{r}23.98 \\
0.77266 \\
21.5679 \\
26.3921\end{array}$ & 0 & $\begin{array}{r}18.825 \\
0.77266 \\
16.4129 \\
21.2371\end{array}$ & $\begin{array}{r}8.675 \\
0.77266 \\
6.2629 \\
11.0871\end{array}$ \\
\hline Nikon & $\begin{array}{r}5.155 \\
0.77266 \\
2.7429\end{array}$ & $\begin{array}{l}-18.825 \\
0.77266 \\
-21.237\end{array}$ & 0 & $\begin{array}{r}-10.15 \\
0.77266 \\
-12.562\end{array}$ \\
\hline
\end{tabular}




\begin{tabular}{|l|r|r|r|r|}
\hline & 7.5671 & -16.413 & 0 & -7.7379 \\
\hline S3 & 15.305 & -8.675 & 10.15 & 0 \\
& 0.77266 & 0.77266 & 0.77266 & 0 \\
& 12.8929 & -11.087 & 7.7379 & 0 \\
& 17.7171 & -6.2629 & 12.5621 & 0 \\
\hline
\end{tabular}

Table 8. Tukey HSD table for Shade tabs.

Level

iPhone 5 A

S3

Nikon

Canon
C

D

\section{Least Sq Mean}

31.200000

22.525000

12.375000

7.220000

Levels not connected by same letter are significantly different

\begin{tabular}{|l|l|l|}
\hline Pair wise & comparison & P-value \\
\hline Nikon & Canon & 0.0169 \\
\hline iPhone 5 & Canon & $<0.0001$ \\
\hline iPhone 5 & Nikon & $<0.0001$ \\
\hline Galaxy S3 & Canon & 0.0006 \\
\hline Galaxy S3 & Nikon & 0.0005 \\
\hline Galaxy S3 & iPhone 5 & $<0.0001$ \\
\hline
\end{tabular}

Table 9. Pairwise comparison of camera for shade tabs images.

\section{DISCUSSION}

In this study, an attempt was made to compare the color accuracy of 4 digital cameras:

The canon EOS 30D, The Nikon D700, The iPhone 5 camera, The Samsung Galaxy S3

Camera. The Null Hypothesis that all 4 cameras will not be significantly different for both 
the colorchecker card and the shade tabs was rejected. The canon EOS 30D, The Nikon D700 and The Samsung Galaxy S3 were not significantly different for the colorcheker image card. This is the first study that attempt color measurement on digital images produced by cellular phone cameras. The iPhone 5 cameras yield the highest $\Delta \mathrm{E}$ values for both the colorchecker card and the shade tabs. One explanation may be the fact that there is no setting choice on the iPhone camera. For example the canon, Nikon and Galaxy S3 could be set on Custom white balance (Sun daylight) while the iPhone 5 does not give any white balance or color temperature setting. Tung et al. (2009) verify the necessity of Custom white balance (CWB) for the digital camera. ${ }^{30}$ They hypothesized that different illuminants and camera's white balance setups shall influence color rendering of digital images and affect the effectiveness of color matching using digital images. They found significantly high correlation coefficients $(\mathrm{r} 2>0.96)$ between the respective spectrophotometer standards and those shade guides generated in CWB setups. In the same study, the authors compared the accuracy of color matching by ten operators of a set of ceramic disks using digital shade guides. They reported that the mean match improved from $67 \%$ in auto white balance (AWB) to $93 \%$ in CWB under LED illuminants. Wee AG et al. (2005) study the color accuracy of 3 digital commercial cameras used in dentistry by measuring color difference of colorchecker card and shade tabs. ${ }^{31}$ In their study, $\Delta \mathrm{E}$ values ranged from 1.79 to 5.25 . The CIELAB values of digital images of the shade tabs and the colorcheker were compare to CIELAB measures of the same color card and same shade guides obtained by a spectroradiomaters. In our study we use the manufacturer adobeRGB values and previously established CIELAB value for the Shade tabs. King et al. concluded that the 
Vitapan Classical Shade Guide tabs should not be considered interchangeable. ${ }^{24}$ In our study, we also analyzed the images in their raw format while Wee and al study converted the digital images in Tiff format prior to analysis. Chu et al. (2010) in their review for different instruments and system for dental color matching noted that the smallest $\Delta \mathrm{E}$ value does not necessarily correspond to the best match because of the uneven eye sensitivity to hue, value and Chroma differences. ${ }^{7}$ In this study, both the iPhone 5 and the galaxy S3 phone cameras color difference values for the shade tabs images were higher than for the Nikon and Canon Delta E values. Some of the Red (R) and green $(G)$ values for the cellular phone camera image for the teeth were 255 (highest value possible) indicating a possibility of a default value by the Photoshop software program. These high values may be explained by the smaller lenses of the cellular phone cameras and the optical properties of the teeth, the shade tabs are curved, multilayered, and translucent and exhibit color transition in all directions. The sample size for the shade tabs was small, only 4 shade tabs were selected, but all the tabs were photographed 3 times giving us enough data for meaningful analysis.

\section{CHAPTER IV: SUMMARY AND CONCLUSIONS}

There is a consensus in the literature about the inconsistency and unreliability of visual shade matching. Color communication to the dental laboratory technician is best performed using reference photography of the targeted tooth together with preselected shade tabs. ${ }^{7}$, ${ }^{32}$ Within the limitations of this study, the iPhone 5 was the least accurate in reproducing color of both the 24 color patches on the colorchecker card and the shade 
tabs. The Canon EOS 30D, the Nikon D700 and the Galaxy S3 cameras have a similar performance for the colorchecker card, lending credence to the notion that white balancing can improve digital image color rendition. Regarding the digital images of shade tabs, the Canon EOS 30D was the most accurate, followed by the NikonD700, the Galaxy S3 and lastly the iPhone 5. While the convenience and general availability of cellular phone cameras is great, within the limitations of this study, their usage is not recommended for digital images of teeth for shade matching purposes.

\section{CHAPTER V: RECOMMENDATIONS}

Future studies may investigate if future advancements in small camera designs will improve the use of cellular phone cameras in the dental setting. 


\section{REFERENCES}

1. Barrett, A. A., Grimaudo, N. J., Anusavice, K. J., \& Yang, M. C. K. (2002). Influence of tab and disk design on shade matching of dental porcelain. The Journal of Prosthetic Dentistry, 88(6), 591-597.

2. Klemetti, E., Matela, A., Haag, P., \& Kononen, M. (2006). Shade selection performed by novice dental professionals and colorimeter. Journal of Oral Rehabilitation, 33(1), 31-35.

3. Hammad, I. A. (2003). Intrarater repeatability of shade selections with two shade guides. The Journal of Prosthetic Dentistry, 89(1), 50-53.

4. Paravina, R. D., O'Neill, P.,N., Swift,Edward J.,,Jr, Nathanson, D., \& Goodacre, C. J. (2010). Teaching of color in predoctoral and postdoctoral dental education in 2009. Journal of Dentistry, 38 Suppl 2 , e34-e40.

5. Schropp, L. (2009). Shade matching assisted by digital photography and computer software. Journal of Prosthodontics: Official Journal of the American College of Prosthodontists, 18(3), 235-241.

6. Okubo, S. R., Kanawati, A., Richards, M. W., \& Childress, S. (1998). Evaluation of visual and instrument shade matching. The Journal of Prosthetic Dentistry, 80(6), 642-648.

7. Chu, S. J., Trushkowsky, R. D., \& Paravina, R. D. (2010). Dental color matching instruments and systems. review of clinical and research aspects. Journal of Dentistry, 38 Suppl 2, e2-e16.

8. Elter, A., Caniklioglu, B., Deger, S., \& Ozen, J. (2005). The reliability of digital cameras for color selection. The International Journal of Prosthodontics, 18(5), 438-440.

9. Schwabacher, W. B., \& Goodkind, R. J. (1990). Three-dimensional color coordinates of natural teeth compared with three shade guides. The Journal of Prosthetic Dentistry, 64(4), 425-431.

10. Cal, E., Sonugelen, M., Guneri, P., Kesercioglu, A., \& Kose, T. (2004). Application of a digital technique in evaluating the reliability of shade guides. Journal of Oral Rehabilitation, 31(5), 483-491.

11. Joiner, A. (2004). Tooth colour: A review of the literature. Journal of Dentistry, 32 Suppl 1, 3-12.

12. Rosenstiel, S., Land, M., \& Fujimoto, J. (2006). Description of color,color replication process, and esthetics. Contemporary fixed prosthodontics (4th edition ed., pp. 709). st Louis: Mosby. 
13. van der Burgt, ,T.P., ten Bosch, ,J.J., Borsboom, P. C., \& Kortsmit, W. J. (1990). A comparison of new and conventional methods for quantification of tooth color. The Journal of Prosthetic Dentistry, 63(2), 155-162.

14. Vaarkamp, J., ten Bosch, ,J.J., \& Verdonschot, E. H. (1995). Propagation of light through human dental enamel and dentine. Caries Research, 29(1), 8-13.

15. ten Bosch, ,J.J., \& Coops, J. C. (1995). Tooth color and reflectance as related to light scattering and enamel hardness. Journal of Dental Research, 74(1), 374-380.

16. Terry, D. A., Geller, W., Tric, O., Anderson, M. J., Tourville, M., \& Kobashigawa, A. (2002). Anatomical form defines color: Function, form, and aesthetics. Practical Procedures \& Aesthetic Dentistry: PPAD, 14(1), 59-67.

17. Seghi, R., \& Johnston, W. (1992). Estimate of colorimetric measurement erros associated with natural tooth color fluorescence. J Dent Res, 71, 303.

18. Sproull, R. C. (2001). Color matching in dentistry. part I. the three-dimensional nature of color. 1973. The Journal of Prosthetic Dentistry, 86(5), 453-457.

19. Sproull, R. C. (2001). Color matching in dentistry. part II. practical applications of the organization of color. 1973. The Journal of Prosthetic Dentistry, 86(5), 458-464.

20. Imbery, T. (2013). Evaluation of four dental clinical spectrophotometers relative to human shade observation. ADA Professional Product Review, 8(3)

21. Kuehni, R., \& Marcus, R. (1979). An experiment in visual scalingof small color differences. Color Res Appl, 4, 83-91

22. Johnston, W. M., \& Kao, E. C. (1989). Assessment of appearance match by visual observation and clinical colorimetry. Journal of Dental Research, 68(5), 819-822.

23. Ragain, J., \& Johnston, W. (2000). Color acceptance of direct dental restorative materials by human observers. Color Res Appl, 25, 278-285

24. King, K. A., \& deRijk, W. G. (2007). Variations of $L^{*} a^{*} b^{*}$ values among vitapan classical shade guides. Journal of Prosthodontics: Official Journal of the American College of Prosthodontists, 16(5), 352-356.

25. Seghi, R. R., Johnston, W. M., \& O'Brien, ,W.J. (1989). Performance assessment of colorimetric devices on dental porcelains. Journal of Dental Research, 68(12), 1755-1759.

26. Douglas, R. D. (1997). Precision of in vivo colorimetric assessments of teeth. The Journal of Prosthetic Dentistry, 77(5), 464-470. 
27. Haywood, V. B., \& Leonard, R. H. (1994). Effectiveness, side-effects and long-term status of nightguard vital bleaching. Journal of the American Dental Association (JADA), 125(9), 1219.

28. Paul, S., Peter, A., Pietrobon, N., \& Hämmerle, ,C.H.F. (2002). Visual and spectrophotometric shade analysis of human teeth. Journal of Dental Research, 81(8), 578-582.

29. Kuo, S. (2003). Color accuracy of digital images for use in craniofacial rehabilitation. (Masters, The Ohio state university).

30. Tung, O., Lai, Y., Ho, Y., Chou, I., \& Lee, S. (2011). Development of digital shade guides for color assessment using a digital camera with ring flashes. Clinical Oral Investigations, 15(1), 49-56.

31. Wee, A. G., Lindsey, D. T., Kuo, S., \& Johnston, W. M. (2006). Color accuracy of commercial digital cameras for use in dentistry. Dental materials, 22, 553-559.

32. Tam, W. K., \& Lee, H. J. (2012). Dental shade matching using a digital camera. Journal of Dentistry, 40 Suppl 2, e3-e10. 